\title{
Interpreting Chinese Culture-Loaded Sayings: A Case Study of Press Conference of Two Sessions
}

\author{
$\mathrm{Jin} \mathrm{Wu}^{1}$ \\ ${ }^{1}$ School of Humanity, Liaoning Radio and TV University, Shenyang, China \\ Correspondence: Jin Wu, School of Humanity, Liaoning Radio and TV University, NO. 3-11, Wenhua Road, \\ Heping District, Shenyang, China. E-mail: 77823457@qq.com
}

Received: July 31, 2019 Accepted: August 25, 2019 Online Published: August 30, 2019

doi:10.5539/ells.v9n3p56 URL: https://doi.org/10.5539/ells.v9n3p56

\begin{abstract}
As an indispensable means to elaborate on China's development momentum and to set up global image, interpretation of press conference for Two Sessions presents the study essence of international publicity translation and the key problems lie in the culture-loaded expression translation. In light of the Functional Linguistics and Functionalist translation theory, the top-down hierarchic problem-solving approach is adopted for the original analysis. The target-oriented perspective aims at acquiring adequate version instead of equivalence between the source and target. The past decade example extractions cover the interpretation of the four-character set phrases, colloquial expressions, quotations and proverbs. Nine frequently-used interpretation types are concluded and analyzed in terms of the intended function and addressees' reception environment by comparing the source and target cultures. Statistic results show that the compatibility between the two cultures may account for, to some extent, the method selection for interpreting practice in question. The more compatible of the relationship between the two cultures, the more tendency of preserving the original cultural image, and the more literal forms will be employed. And the larger the cultural distance, the more adjustments and adaptions would be adopted. With due consideration of the intentional function and addressees' background, the versions may be readily accepted.
\end{abstract}

Keywords: interpretation, press conference of Two Sessions, Functionalist theory, culture-loaded sayings, translation strategy

\section{Introduction}

Interpretation, as a specific branch of translation, can be defined by many distinctive features, such as only once presentation, transitory source and target texts and shared contextual conditions between the source and target languages. The interpreting of press conferences in China possesses certain characteristics that may pose unique influence on the translation process and strategy choices. The interpreting of international publicity can usually resort to consecutive interpretation. Among all types of press conferences held within China, the annual press conference after the Two Sessions (NPC and CPPCC) exerts the most representative impact on the international media. Undeniably, it is one of the most prominent occasions to update the political, economic and foreign policies and development trends of China. The interpreting practice for Two sessions' press conference may provide valuable materials for translation study and training.

In the past decade, with one exception in 2013, Ms. Zhang Lu, senior Interpreter in the Ministry of Foreign Affairs, has been serving as an impressive and qualified interpreter for Premiers of China in Two Sessions' Press Conferences. As can be easily traced, the speakers (Premiers of China) may frequently refer to some set phrases, colloquial expressions, famous sayings and quotations to describe the content of messages they meant to convey. Some of them are as readily acceptable as those to English audiences, while others are original to the journalists from other parts of the world. This paper aims to classify and explore the translation process and strategies in those culture-loading sayings in Press Conference with examples taken from China's Two sessions in the past decade (2010-2019).

\section{Literature Review}

The interpretation of these classical sayings or quotations in Press Conferences is quite different from that in written translation. As the communicative purpose, target readers, context are distinctive, the rendering process, 
principle and strategies may be separately analyzed.

\subsection{Literature Review of Translation Studies on Culture-Loaded Words}

For the literature review of the translation study of the culture-loaded words in various styles of source texts, several schools have touched this field. The translation methods of Chinese culture-loaded words are mainly discussed in the literary works, especially those well-known novels, poems and classics, for the cultural image are endowed with more expectation from the English readers. As can be summarized, the strategies and methods include literal translation, free translation, transliteration, literal translation plus annotation, partial translation and direct borrowing. Some adaption translations, such as correspondence, interpretation and reduction, are also uncovered in certain cultural contexts (Guo, 2019, pp. 22-27).

Also, the interpretative translation from the interpretive theory, which aimed to "deverbalize from the original" and "reverbalize in the target" on the basis of sense equivalence of discourse is discussed (Seleskovitch, 1978). From pragmatic perspective, adaption translation declared the dynamic adaption from contextual elements (Verschueren, 2000, p. 55). The other scholars turned to the translator's subjectivity for the press conference interpretation, which covered the political sensibility, diplomatic awareness and the trans-cultural communicative translation (Cha \& Tian, 2003, pp. 19-24). Most of the above-mentioned studies have involved the relationship between the source and target text. Trying to achieve "equivalence" (Nida, 2004) in certain aspect, the source text actually takes precedence over the target text. Generally speaking, "equivalence" is a static, result-oriented concept describing a relationship of "equal communicative value" between two texts or on lower ranks - linguistic units.

\subsection{Literature Review of Functional Studies}

Based on the Functional linguistics study, Huang Guowen proposed an empirical research pattern for functional discourse analysis. The six-part format covers observation, interpretation, description, analysis, explanation and evaluation (Huang, 2004, p. 17). Because of the similar theoretical origin, it can be applied to the problem-solving or evaluation of translation practice.

As a semantic unit, discourse may possess a flexible length, whether in spoken or written form. It is a form of language in use, so the functioning context for discourses should be interpreted. A discourse consists of three aspects, cultural context, situational context and language (Huang, 2002, pp. 22-28).

After due observation and selection, the research target of the translation works may be interpreted by analyzing the conveying meaning, communicative purpose and communicated results of the discourse in question. Under the guidance of functional discourse analysis, it can be evaluated that whether the rendered discourse achieved the intended purpose or not, and in which aspect it can be defined as a successful translation or as an unsatisfactory work. In most cases, it is indeed hard to achieve the adequate effect, for the translator should take "the cultural context", "the situational context" as well as the relationship between discourse and contexts into consideration.

On the other hand, some researchers referred to the Functionalist Theory. Originated from German translation schools, Functionalist theory sheds comprehensive light on translation studies and practice. With its unique definition of translation as "to produce a text in a target setting for a target purpose and target addresses in target circumstances" (Vermeer, 1987, p. 29). The original analysis and translation action may be conducted in accordance with the intentional functions and the target culture serves as the top priority, not the source culture.

This paper tends to explore the interpretation process and strategy and method employment of press conference for Two Sessions under the framework of Functionalist Theory. By comparing the source and target cultures, specific samples with culture-loaded sayings will be analyzed. And the relationship between the two cultures as well as the identification of intentional functions of the translation should be considered at length for an adequate version.

\section{Theory Application of Functionalist Framework to Press Conference Interpretation}

\subsection{Key Concept Definition}

For the validity of the theoretical explanation, some key concepts of the Functionalist theory should be clarified.

Skopos: what the translator is aiming at in the translation process;

Function: what the text means to a particular reader in a particular moment of reception;

Translation Brief: to define the purpose that the translation is intended to achieve in the target culture.

Adequacy: the qualities of a target text with regard to the translation brief: the version should be "adequate to" 
the requirements of the brief. It is a dynamic concept related to the process of translational action and referring to the "goal-oriented selection of signs that are considered appropriate for the communicative purpose defined in the translation assignment." (Reiss, 1989, p. 163)

Under the framework of Functionalism, Nord proposed that translation types can be distinguished between "documentary" and "instrumental". There are several forms for both translation types. The author selected several forms in need of the samples selected.

Literal or grammar translation: if a documentary translation is intended to reproduce the words of the original by adapting syntactic structures and idiomatic use of vocabulary to the norms of the target language, we may call it a literal or grammar translation.

Philological or learned translation: if a documentary translation reproduces the source text rather literally but adds the necessary explanation about the source culture or some peculiarities of the source language in footnotes or glosses, we may speak of philological or learned translation. The current study named it as "literal translation with gloss".

Homologous translation: as a form of instrumental translation, the tertium comparationis between the source and target text is a certain status within a corpus or system, mostly with respect to literal or poetic texts. The target text might be supposed to represent the same, or a homologous, degree of originality as the original with regard to the respective culture-specific corpora of texts. It is termed by Jakobson as "creative translation". It is currently employed as "transcreation" with the emphasis on the change of form and content in the target version but with the same intentional function. Though it is often excluded from the realm of translation proper, for functionalism they obey a specific Skopos and are thus just as any other form of intercultural transfer. And it is considered as a method of free translation.

The main translation strategies in this study are literal and free translation. As for the other specific forms, such as addition, direct borrowing, literal plus gloss, generalization, zero translation and transcreation, are the translation methods under their spectrum. For the convenience of statistic analysis and to avoid misunderstanding, the author changes the translation strategies and methods to translation types in practice.

\subsection{Basic Principle}

Nord's version of the functionalist approach stands on "function plus loyalty". Function refers to "the factors that make a target text work in the intended way in the target situation". Loyalty, different from such terms as fidelity or faithfulness which focus on the relationship between the source and the target text, refers to the interpersonal relationship between the translator, the source-text sender, the target-text addressees and the initiator.

The interpreter first sets Translation Brief, which defines the translation purpose, according to the translational intention in the target culture. Taking due responsibility in the cooperative activity of translation, the interpreter conducts the original text analysis, both from intertextual and intratextual situations. Finally, the translated message may be realized by adopting a top-down hierarchic problem-solving approach which is discussed in the next section.

\subsection{Theoretical Application}

For the interpretation of press conferences for the Two Sessions, the original producer and translator share the common intention and aim at the same target function. However, as Premier in China delivered massage from traditional Chinese thinking mode and social-cultural background. When the conveyed information contains some cultural conflict with Chinese characteristics, the interpreter should take the responsibility to negotiate as the representative for both the source-text producers and the target-text receivers. As the essential translation in the press conferences in question is from Chinese to English, the version should be target-oriented and put the foreign journalists' reception as top priority. It is more crucial when it comes to the interpretation of bilateral relationship, international cooperation and friendly image of China.

Form the above analysis, it can be concluded that the Translation Brief in this study should be as following:

Reason for interpretation: official news release;

Prospective target function:

1) Informative: to deliver China's economic and political viewpoints and stand;

2) Operative: to call for international attention to build China's image

Target text receiver: the domestic and foreign journalists, with emphasis on the latter;

Reception situation: annual press conference after Two Sessions in mid-March. 


\section{Interpretation Types for Culture-Loaded Sayings}

In light of the translation brief concluded above, the interpreter will select certain method(s) to achieve the target function at the moment of reception. The Functionalist theory guides translational act and analysis to materialize the informative and operative functions (Reiss, 1977, pp. 105-115) of press conferences.

To identify the problems and choose appropriate strategies for interpretation, the interpreter may adopt "the top-down approach" under the Functionalism. It means that translation act should start on the pragmatic level by analyzing the intended function of interpretation whether documentary or instrumental (Nord, 2001, p. 68). Then a classification is made among the functional elements from the original text. Some may be reproduced "as such", while others may be adapted to the target addressees' background, including their knowledge, expectations and communicative needs. Also, decisions should be made after the analysis of such factors as medium-restrictions and deixis requirements. The top-down Functionalist approach is demonstrated in Figure 1.

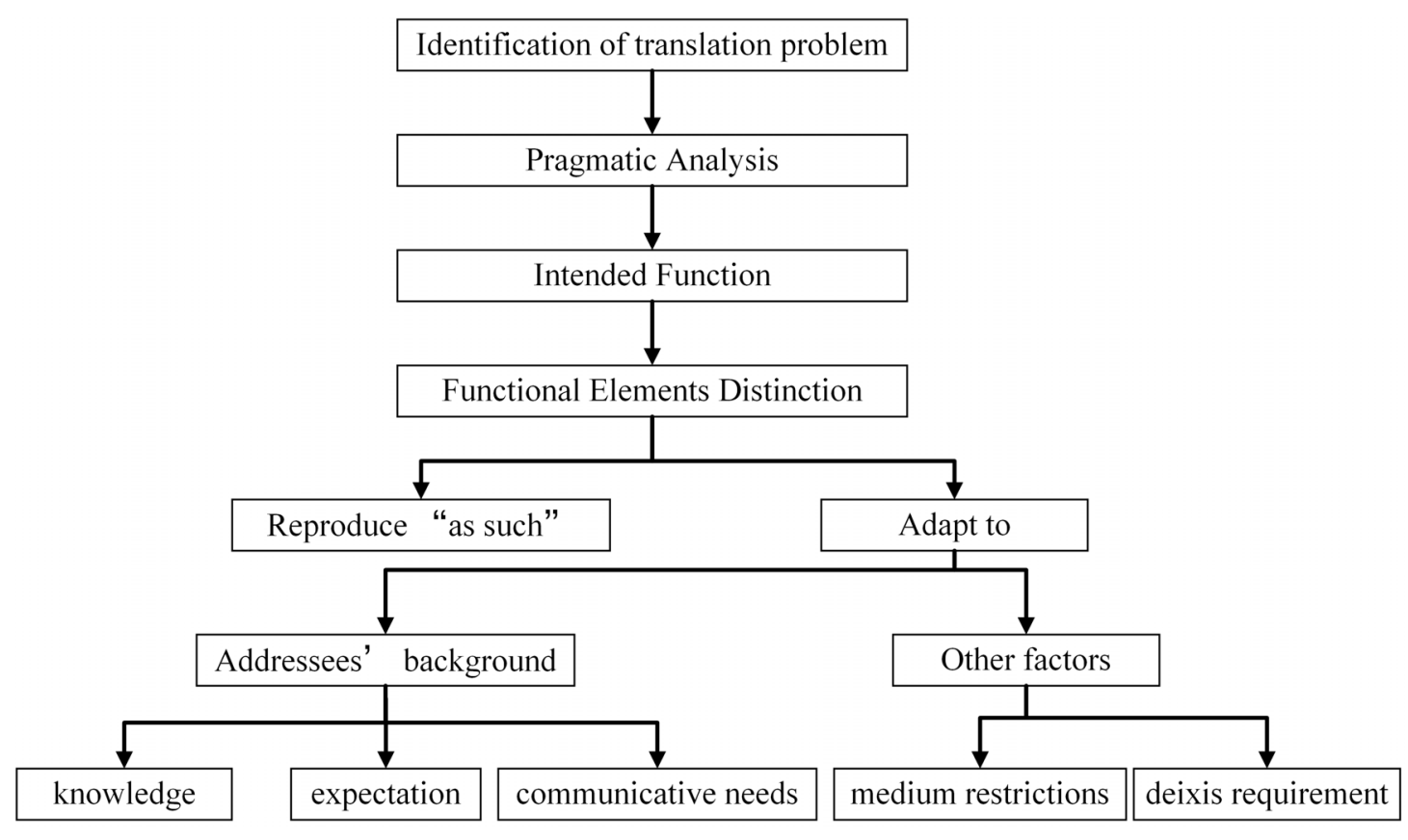

Figure1. Top-down problem-solving approach

In light of the Functional Linguistics, the discourse analysis, as well as the translation analysis in this case, may also adopt a top-down pattern from the perspective of linguistic studies (Huang, 2002, p. 28).

And from Huang's research results, the general steps of translation discourse analysis may be summarized as followed:

A. Cultural context (discourse typology: schematic structure and realizational pattern)

B. Situational context (register: field, tenor and mode)

C. Semantics (metafunctions: ideational, interpersonal and textual)

D. Language (lexico-grammar, phonology and graphology)

This analysis procedure is added to the translation pattern from the functional linguistic perspective, along with that from the Functionalist translation theory. The translator may make a choice whether to abandon the communicative value relevant to the context and keep formal equivalence; or to abandon the semantic equivalence irrelevant to the context and keep the communicative functions. In other words, the choice is between literal and free translation. In practice, the construction of a translated discourse which is accessible to the target community, is dependent on the intentional selection from linguistic resources in a top-down manner with regard to the communicative functions.

\subsection{Scope of Illustration for Interpretation Strategies and Methods}

The current analysis for selection of interpretation types is conducted with the extraction from the typical and 
regular culture-loaded information in the press conference of Two Sessions (2010-2019). The examples highlight such stylistic components as the four-character set phrases, colloquial expressions, quotations and proverbs/sayings because these are most frequently employed components by the speakers and most representative for cultural context translation from Chinese to English.

\subsection{Statistic Classification of Strategy and Method Use}

From the literature review and transcript of interpretation practice, seventy-two examples are extracted. The strategies employed for illustrations mainly cover literal translation and free translation. And under the strategic guidance, several specific translation methods are used: literal translation plus gloss, addition, direct borrowing, generalization, transcreation and zero translation. One example, usually taking sentence(s) as unit, may resort to one or more interpretation methods. However, considering the research clarity and comprehensibility, only the most prominent method for one example is analyzed and classified. The statistic results of translation types by the stylistic features are shown in Table 1.

Table 1. Statistic display of interpreting types

\begin{tabular}{|c|c|c|c|c|c|c|c|c|c|}
\hline original style types & literal & $\begin{array}{l}\text { direct } \\
\text { borrowing }\end{array}$ & $\begin{array}{l}\text { literal + } \\
\text { gloss }\end{array}$ & free & addition & $\begin{array}{l}\text { generali- } \\
\text { zation }\end{array}$ & $\begin{array}{l}\text { trans- } \\
\text { creation }\end{array}$ & $\begin{array}{l}\text { zero } \\
\text { translation }\end{array}$ & $\begin{array}{l}\text { trans- } \\
\text { editing }\end{array}$ \\
\hline four-character set phrases & 3 & & 1 & 6 & & & & 1 & \\
\hline colloquial/dialect & & & 4 & 20 & & & 1 & & 1 \\
\hline quotation & 13 & 1 & 1 & 5 & 2 & 1 & & & \\
\hline proverb/saying & 7 & 2 & & 1 & & & 1 & & 1 \\
\hline Total & 23 & 3 & 6 & 32 & 2 & 1 & 2 & 1 & 2 \\
\hline
\end{tabular}

Note. The samples collected from interpretation practice amount to 72 cases.

\subsection{Analysis of Statistic Results}

First, for the four-character set phrases in the original, six examples adopted free translation, which was doubled as the literal translation illustrations. One case resorted to literal translation plus annotation and one to zero translation. Though set phrases contain much cultural and historical information, most of them require considerable contextual explanation and are of little relevance to the intentional function. Therefore, the interpreter chose free translation more often than others.

Second, for the colloquial or dialectical expressions, there are two main forms, direct utterance in the speech and the implied expressions embedded within the metaphors. As for the direct forms, free translation covered most of the cases, eight out of ten. For the embedded cultural expressions in some metaphors, fifteen out of twenty-eight cases, used free translation or literal translation plus gloss because of the lack of cultural background for the addressees. One case employed trans-editing, as is discussed in detail later, for cultural image may be partially kept under the intentional function guidance. As a non-literary typology, there is no need to amplify the comprehension difficulty for the target addressees. Also, it will be no harm to achieve the informative or operative function of the translation.

Third, in terms of the quotations which may be the most demanding challenge for interpreters, more than half cases adopted literal translation in consideration of the full transformation of Chinese cultural information. Also, some contexts may exert negative influence on the target acceptance so other methods came into play, such as adaption translation, addition and generalization.

Last but not least, Chinese proverbs or sayings were dealt with literal translation most (seven out of twelve). As proverbs and sayings are typical manifestation of traditional Chinese culture and concepts, it will be of great use for cultural communication and international image publicity. And two cases of direct borrowing of western cultural context and one case of transcreation demonstrated that Chinese and English culture may share some concepts or image because of the efficient exchanges.

\section{Sample Demonstration with Analysis}

From the above statistics and data results, we may come to the following conclusions. In view of Functionalist guidance to realize the intended function of the target text, interpretative process and strategy or method should be conducted with the precedence of the target culture and addressees' reception conditions. The decision made on certain method selection can be attributed to the following aspects. 


\subsection{Degree of Content Completeness}

First, as for the degree of content transferring, the interpreter may adopt full translation (as in faithful translation, or word-for-word translation), summary translation (as in generalization or omission) and trans-editing (as in addition or adaption translation).

\subsection{Target Culture-Oriented Comparison}

Second, in comparison between the source and target culture, certain methods were selected with the target culture aimed approach.

\subsubsection{Readily Compatible Context}

In a mutually compatible context, literal translation or direct borrowing of target cultural concepts can be used.

For instance, in press conference of 2012 and 2013 on the cross-straits ties, Premier Wen quoted one poem:

[1] “情天再补虽无术, 缺月重圆会有时” (Zhang Lu's version: there is no way to mend the heal in my heart, but there will be a day when the half moon becomes full again).

He said twice “full moon” (as “月圆”, “重圆” in the original) to imply the reunion will surely be achieved. The western culture possesses the similar symbolic meaning of "full moon"-harvest and perfection. The compatible cultural indication made the interpreter choose literal translation strategy.

Another case comes from the example in 2018 press conference.

[2]Original text: “这些都是动政府“奶酪”的, 是伤筋动骨的改革。”

Zhang's version: "This is like moving the government's own cheese."

It concerns the reduction of fees and taxation. From the perspective of the cultural communication exchange between the East and the West, the interpreter directly borrowed the addressees' western cultural knowledge of a famous novel "Who Moved My Cheese?" by Spencer Johnson. In both the source and target contexts, "cheese" can be readily accepted as "real benefit or interest" so direct borrowing is selected.

\subsubsection{Endeavor-Cost Cultural Context}

As is often encountered in translation practice, there is hardly any perfect match in the target context, especially from the Chinese set phrases and colloquial expressions. However, for the purpose of designed functions, the interpreter should try every possible means to make adjustments in the version production process.

An example for illustration was found in 2011 press conference.

[3] Original: “如将不尽, 与古为新。”

Original meaning: As human beings can infinitely explore the nature, the ancient poems should resort to constant creation of poetic imagery.

Zhang's version: "It is only with reform that we can ensure continuous existence and growth."

It is originated from Twenty-four modes of Poetry Chinese literature by Si Kongtu in the Tang Dynasty. The quotation focused on the possibility and importance of creation. The current context indicated the importance of reform, so the interpreter converted the essence of ancient poems to the reform of new era. The old concept was adapted to new context with the same emphasis on creation so the communicative needs is acquired.

In some cases, due to the the linguistic and contextual difference, the rendered text may add, omit or generalize some information. For some indispensable context information which is of assistance to the designed function of the target, it is acceptable to insert additional message or personify the original.

[4] For instance, “政如农工, 日夜思之，思其始而成其终。”（extracted from 2011 press conference）

Zhang's interpretation: " $I$ do my job diligently as a farmer tends to his field. $I$ have it on my mind day and night. $I$ work for a thorough planning at the start and $I$ am determined to carry it through to a successful end."

Quoted from Zuo Zhuan, a Confucian historical biography and classic, Premier Wen intended to show his dedication and persistence for the well being of Chinese people. The subject " $\mathrm{I}$ " was added to the version, and such underlined adjectives as "thorough", "determined", "successful" were also complementary to the context. The implied meaning was filled out and more comprehensible in terms of Premier's insistence and working attitude.

When the translated text aimed to keep the cultural terms of the original but also anticipated the difficulty in the target audiences' understanding, the literal plus descriptive method can come into play. One example was from 


\section{7 press conference.}

[5]The source text: “不是靠政府去提供“铁饭碗”, 而是让人民群众用劳动和智慧去创造或者说打造“金饭 碗”。”

The target text: "The government's job is not to hand out the "iron rice bowl" or permanent jobs to the people, but to create enabling conditions for the people to use their own ingenuity and hard work to create or secure "gold rice bowls" so to speak".

In the original, "iron rice bowl" is a term produced in the planned economy stage of China, which means evenly-assigned and equal-payment job. While "gold rice bowl" is a term originated from the market directed economy stage of China, which means a decent and well-paid job. To preserve the effect of contrast in the version, the literal form of the two terms were kept, and some descriptive explanation were inserted, "permanent job" for the "iron rice bowl", and "so to speak" for "gold rice bowl".

On the other hand, some unnecessary information for the function of the version should be omitted or generalized considering the workload and time pressure of interpretation. A case in point lies in a quotation in 2010 press conference.

[6]Original: “华山再高, 顶有过路。”

Zhang's version: "No matter how high the mountain is; one can always ascend to its top."

In this context, the original took Mount Hua as an illustration for the demanding difficulties in our development. Mount Hua, also called Xi Yue (“西岳”), or Taihua Mount (“太华山”)，is regarded as the most dangerous mountain to climb. Located in Shaanxi Province in China, Mount Hua possessed long history and is considered as one of the cradles of Chinese civilization. However, the interpreter, as also foreseen by the target receivers, deleted the specific example of Mount Hua, and generalized the translation by using a higher-class phrase "the mountain". Also, the core meaning was communicated without any culture barriers.

\subsubsection{Void Equivalence Cultural Context}

In some cases, the original stylistic elements are irrelevant to the acceptance of the version or account little for the designed function of the target. The interpreter may resort to zero translation, transcreation or trans-editing.

A case for zero translation is extracted from 2016 press conference.

[7]The original reads “很高兴能够一石三鸟, 不过不是打, 是问。哦不, 是打....... 简政放权可以说是转变 政府职能的关键。就在这里, 三年前, 我曾经明确表示, 本届政府减少审批事项要达到 $1 / 3$, 现在这个目 标已经实现。根据第三方的评估, 大部分企业和群众还满意的。但是确实存在一些问题, 存在更高的期 待。”

Zhang's version: "To streamline administration and delegate powers holds the key to transforming government functions. Three years ago, on the same occasion, I promised that this government will cut the number of items that required state council review and approval by one third during its term. And now we have already fulfilled this target. And based on third party evaluations, most of the companies and our people are satisfied with the progress of the reform. Yet still some problems exist and our people expect more from the government."

The underlined part of the original was not interpreted because the speaker used a revised set phrase “一石三鸟” ( originally cited as “一石二鸟”- to kill two birds with one stone) to stress the information of “三” ("three") in the following context. As indicated in the source text, "three" covered three main aspects-three years ago, one third and third party, which required no additional communication requirements for the target receivers. If the interpreter chose to elaborate on this message, it will be redundant and time-consuming for the addressees.

Another case is for transcreation. Also in 2016 press conference, the original reads :

[8] “人们不是常说“人在做、天在看”吗? 现在是云计算的时代, 我们要让“权在用、云在看”, 行使权力不 能打小算盘。”

Zhang's version: "People used to say that "As man is doing, heaven is watching." I guess in this era of cloud computing, it should be, "Cloud is watching, watching how power is being used," and in the exercise of power by governmental departments, there should be no practice of making calculating moves for personal gain."

Premier made use of this common saying to justify that the governmental departments should properly exercise powers at hand. The sentence pattern remained the same, and the grammar structure "is doing" and "is watching" are diverted to "is watching" and "is being used". The intentional meaning is delivered with the original stylistic format. It is a sound demonstration to satisfy the addressees' expectations of representing both format and meaning of the source context. 
For the foreign journalists, some key cultural concepts are comprehensible, but others are not familiar expressions. During the translation analysis of the functional elements, the rendering should be adjusted and edited for both "the intertextual and intratextual coherence" (Nord, 2001, pp. 31-32). In 2017 press conference, Premier Li used a colloquial metaphor to explain the complex and time-consuming administrative approval for project application.

[9] Original: “曾有人展示了一个项目审批“万里长征图”, 据说现在变成“百里”了, 百里也不短啊, 还要继 续推进。”

Zhang's version: "A delegate at the Two Sessions produced a so-called Long-March matrix, showing all the intricate procedures for administrative approval. Although things have been streamlined significantly and the long march has been substantially reduced, it's still too much."

The "Long March" is quite well-known for many foreigners, but the length unit comparison between “万里” (ten thousand li) and “百里” (one hundred li) may be strange to them. In ancient China, li is one of the length units, which is equal to 500 metres for calculation. The original context reduced the ten thousand li to one hundred li to show the streamlined approval process. The interpreter preserved the "Long March" and edited the length comparison to "substantially reduce" to achieve the same communicative effect.

After the comparison between the source and target cultures, the classification of interpreting types can be concluded in Table 2. The more compatible of the cultural relationships, the more literal of the adopted interpreting types. And as long as it is in line with the intentional function, the target text should be readily accepted and responded.

Table 2. Translation type distribution under compared cultural relationships

\begin{tabular}{lll}
\hline mutually compatible contexts & endeavor-cost contexts & void equivalence contexts \\
\hline literal translation & free translation & zero translation \\
direct borrowing & literal translation plus gloss & transcreation \\
& addition & trans-editing \\
& generalization & \\
\hline
\end{tabular}

\subsection{Other Considerations}

Considering the special occasion of the Two Sessions, the translator should possess some political sensitivity from the perspective of China's publicity and stand on the crucial issues. Some alteration or adaption are made in this regard. A case in point is from the 2011 press conference.

[10]The source text: “兄弟虽有小念, 不废懿亲, 问题总会解决的。”

Zhang's version: "But differences between brothers cannot server their blood ties, and I believe that problems will eventually be solved."

The original was concerning the cross-straits ties and Premier displayed the confidence and determination for the reunion. The interpreter adopted literal method in general. However, as for the word “小忿”, which literally means hatred or anger, the interpreter employed “difference" to convey “小忿”, with emphasis on the political stand of China. Taiwan may be somewhat different, but we should seek common ground for two sides of the Strait. The alteration of the implied meaning was necessary and appropriate.

Some cultural terms also should be edited after identifying the speaker's function of the target. In 2013 press conference, Premier was asked about his life experience.

[11] He replied: “我曾经是安徽凤阳的插队知青, 很难忘那一段和乡亲们度过的艰难岁月。”

Zhang's version: "I was once a sent-down youth in Fengyang county in Anhui province. I won't forget the hard times I have spent with the local persons."

The cultural term “插队知青”, if literally rendered as “queue-jumping youth would be quite misleading, was adjusted as" sent-down youth". The confused and incomprehensible literal version was ignored as the following context provided the conceptual meaning of it. Nevertheless, if this case is for written translation, maybe a descriptive approach can come into play: "a school graduate who was sent to live and work in the countryside as a member of rural production team."

As is indicated in Functionalist theory, the translator should identify the intentional function of the target text in accordance with requirements of the initiator, or the speaker in this study (Pöchhacker, 1995, pp. 31-37). It is of 
great importance to obtain a sound prospective function judgement of the speaker. However, the culture-loaded sayings, especially for the classic quotations, are indeed difficult to command precisely. The following instance showed an improper treatment of a quotation.

[12]The source text: “行百里者半九十。”(2010 press conference)

Zhang's version: "That is half of the people who have embarked on a one hundred-mile journey may fall by the wayside."

Original meaning: The last leg of a journey marks the halfway point. (The implied meaning: The last part of an endeavor is the hardest to finish. One must sustain one's effort when a task is nearing completion.)

The sentence was cited from Strategies of the Warring States and the contextual indication of the translation may be suggested as: The following several years will also witness great challenges and obstacles from global financial crisis. Also, we should not slacken our efforts in the slightest, and not waiver in our resolve. "fall by the wayside" is an English proverb means to leave things halfway done. But the intention of the original may be diverted from what we concluded as the intention of the translation.

There is one-point worth clarifying: it is a common case for translation practice to employ more than one strategy in a single translation unit. As for the study samples in question, literal translation and descriptive translation, generalization and trans-editing, omission, non-translation and summary translation are usually combined as strategy groups for the purpose of designed function of the target.

\section{Discussion}

The samples extracted from the past decade practice highlight nine interpreting strategies employed. The decision-making on choice of certain strategy lies in both the intentional function of the translation and the compatibility between the two cultures. Also, the top-down hierarchic problem-solving approach under Functionalism plays indispensable role for international publicity translation.

\subsection{Findings}

The study in question will expand practical research for diplomatic interpretation. The former studies pursued "equivalence" between the source and target texts, which essentially put the original as top priority and ignored the factors related to the acceptance of the translated version. The Functionalist Theory tends to be target-originated and to realize the function of text with due consideration of the receivers' background and target cultural environment.

The research of press conference interpretation of Two Sessions under Functionalism may shed light on the translating process and evaluation principle for this style. For the application of Translation Brief, analysis of the original and functional hierarchy of translation problems, the empirical methods or strategy study may be granted with a more scientific and feasible mode for the processing and evaluating of versions.

The cross-cultural interaction study in this paper may provide certain guidance for the materials in relative fields. The designed communicative information for Two Sessions' press conference may cover the study essence for such styles as diplomatic, political, economic and some international cultural exchanges.

Considering the time and workload pressure, the interpreter may select strategies that can be readily acceptable to the target receivers. The yardstick for the specific strategy choice lies in the expected endeavor-cost and target communicative needs between the original and target cultures. Also, one or mixed methods may be selected. The combination of strategies and translation processing can serve as another topic worth in-depth study.

\subsection{Limitations}

As are listed for discussion, the examples are extracted from the press conferences of Two Sessions from 2010 to 2019. It may not cover all the translation procedures or strategies employed, though it is of some assistance for the interpretation study or training in this domain.

The past decade version examples mainly belong to the works of Zhang $\mathrm{Lu}$, and the source-text producers are Premiers of China, Premier Wen Jiabao and Premier Li Keqiang. Also, some similarity of translation skills and selection of strategies may be found in practice. In perspective of translators' subjectivity, the current study may provide just individual evidence, not comprehensive or universal guidelines.

The current research is basically conducted under the framework of Functionalist theory. As a matter of fact, there are many other theoretical schools applicable to this topic, such as Relevance theory, the interpretative theory of translation, translator's subjectivity and the theory of adaption. All of the branches may deserve further exploration and in-depth practical analysis. Nonetheless, the conclusions and findings may be of great value to 
the relative diplomatic, economic and political exchanges.

The study of interpreting process and strategy is conducted with the target culture-oriented approach and in terms of the addresses' receiving situation. However, it is currently unable to implement the empirical study of the quantitative analysis for the version acceptance.

\section{Acknowledgments}

This research is financially supported by Liaoning Radio and TV University. I am truly grateful to Prof. Shuai $\mathrm{Xu}$ and Prof. Kenan Lin for their assistance in my project.

\section{References}

Cha, J., \& Tian, Y. (2003). On the Subjectivity of the Translator. Chinese Translators Journal, 1.

Full text of 2010 press conference of Two Sessions. (2011). Retrieved March 22, 2011, from https://wenku.baidu.com/view/8a35f209763231126edb11f8.html?rec_flag=default\&sxts=1565161210374

Full text of 2011 press conference of Two Sessions. (2011). Retrieved October 29, 2011, from https://wenku.baidu.com/view/164f2083d4d8d15abe234e54.html

Full text of 2012 press conference of Two Sessions. (2014). Retrieved May, 27, 2014, from https://wenku.baidu.com/view/9cc4e499c1c708a1284a44f5.html

Full text of 2013 press conference of Two Sessions. (2014). Retrieved March 27, 2014, from https://wenku.baidu.com/view/48ba8c8389eb172ded63b7d0.html

Full text of 2014 press conference of Two Sessions. (2014). Retrieved March 19. 2014, from http://language.chinadaily.com.cn/2014npccppcc/2014-03/19/content_17362487.htm

Full text of 2015 press conference of Two Sessions. (2015). Retrieved April 28, 2015, from https://wenku.baidu.com/view/fc7d496814791711cc7917eb.html

Full text of 2016 press conference of Two Sessions. (2016). Retrieved March 16, 2016, from https://language.chinadaily.com.cn/a/201603/16/WS5b20c401a31001b825721173.html

Full text of 2017 press conference of Two Sessions. (2017). Retrieved from https://www.docin.com/p-1909752820.html

Full text of 2018 press conference of Two Sessions. (2018). Retrieved April 19, 2019, from http://www.etogether.net/htm/foreignAffairs/20180419/5174.html

Full text of 2019 press conference of Two Sessions. (2019). Retrieved March 19, 2019, from https://language.chinadaily.com.cn/a/201803/19/WS5c904fa5a3106c65c34ef63a_1.html

Guo, Z. (2019). Translation strategies of culture-loaded words in The Legend of Zhen Huan from the perspective of Skopos Theory. Master's thesis, Beijing Foreign Studies University, Beijing, China. Retrieved from http://kns.cnki.net/kns/ViewPage/viewsave.aspx

Huang, G. W. (2002). Functional Discourse Analysis. Foreign Language Teaching Abroad, 4, 25-32. https://doi.org/10.3969/j.issn.1674-1234.2002.04.007

Huang, G. W. (2004). A Functional Linguistics Approach to Translation Studies. Chinese Translators Journal, 5.

Nida, E. A., \& Taber, R. T. (2004). The theory and practice of translation. Shanghai: Shanghai Foreign Language Education Press.

Nord, C. (1991). Skopos, loyalty and translational conventions. Target. International Journal of Translation Studies, 3(1), 91-109. https://doi.org/10.1075/target.3.1.06nor

Nord, C. (2001). Translating as a purposeful activity: Functionalist approaches explained. Shanghai: Shanghai Foreign Language Education Press.

Pöchhacker, F. (1995). Simultaneous interpretation: A Functionalist perspective. HERMES-Journal of Language and Communication in Business, 14, 31-53. https://doi.org/10.7146/hjlcb.v8i14.25094

Reiss, K. (1983). Adequacy and equivalence in translation. The Bible Translator (technical papers), 3, 301-308. https://doi.org/10.1177/026009358303400301

Reiss, K. (1977). Text types, translation types and translation assessment (Chesterman ed., pp. 105-115).

Seleskovitch, D. (1978). Interpreting for International Conference. Stephaine Dailey and Norman Mcmillan. Washington: Pen and Booth. 
Vermeer, H. J. (1987). What does it mean to translate? Indian Journal of Applied Linguistics, 13(2), 25-33.

Verschueren, J. (2000). Understanding pragmatics. Beijing: Foreign Language Teaching and Research Press. Edward Arnold (Publishers) Limited.

\section{Copyrights}

Copyright for this article is retained by the author, with first publication rights granted to the journal.

This is an open-access article distributed under the terms and conditions of the Creative Commons Attribution license (http://creativecommons.org/licenses/by/4.0/). 